\title{
KONSEP PENDIDIKAN ISLAM ANAK USIA DINI PERSPEKTIF AL-GHAZALI DAN ABDULLAH NASHIH ULWAN (Studi Komparasi Pemikiran)
}

\author{
Siti Alfiah \\ Institut Agama Islam Negeri Ponorogo \\ Email: alfiahsiti2208@gmail.com
}

\begin{abstract}
Education is fundamental in improving the welfare of the nation, because education is a place for moral cultivation, good character, independence, and other knowledge. Al-Ghazali is one of the leaders of classical Islamic thought who is a Sufism thinker and many of the expertise he mastered, one of which is dubbed as Hujjatul Islam (defender of Islam) and Imam al-Murabbin (Expert in Education), while Abdullah Nashih Ulwan is a figure of modern thought in in the world of education. He was the first person to introduce Tarbiyah Islamiyah subjects which were used as basic lessons in school. This study aims to determine the similarities and differences of early childhood Islamic education from the perspective of Al-Ghazali and Abdullah Nashih Ulwan. This research was conducted using a qualitative approach. This type of research is library research (library research). Data collection techniques used were using the documentation method. Data analysis techniques using content analysis techniques. The results of this study are similarities and differences in the concept of early childhood Islamic education from the perspective of Al-Ghazali and Abdullah Nashih Ulwan.
\end{abstract}

Keywords: early childhood Islamic education, Al-Ghazali, Abdullah Nashih Ulwan

Abstrak: Pendidikan merupakan hal yang mendasar dalam meningkatkan kesejahteraan bangsa, karena pendidikan merupakan tempat penanaman moral, akhlak yang baik, kemandirian, serta pengetahuan yang lainnya. Al-Ghazali merupakan salah satu tokoh pemikiran Islam klasik yang merupakan pemikir tasawuf serta banyak keahlian yang dikuasainya salah satunya di juluki sebagai Hujjatul Islam (pembela Islam) dan Imam alMurabbin (Pakar bidang Pendidikan), sedangkan Abdullah Nashih Ulwan merupakan tokoh pemikiran modern di dalam dunia pendidikan. Beliau adalah orang pertama kali yang memperkenalkan mata pelajaran Tarbiyah Islamiyah yang digunakan sebagai pelajaran dasar di sekolah. Penelitian ini bertujuan untuk mengetahui persamaan dan perbedaan dari pendidikan islam anak usia dini perspektif Al-Ghazali dan Abdullah Nashih Ulwan. Penelitian ini dilakukan dengan menggunakan pendekatan kualitatif. Jenis penelitiannya adalah penelitian kepustakaan (library research). Teknik pengumpulan data yang digunakan menggunakan metode dokumentasi. Teknik analisis data menggunakan teknik analisis isi (content analisys). Hasil dari penelitian ini terdapat persamaan dan perbedaan dalam konsep pendidikan islam anak usia dini perspektif Al-Ghazali dan Abdullah Nashih Ulwan.

Kata kunci: pendidikan islam anak usia dini, Al-Ghazali, Abdullah Nashih Ulwan

\section{PENDAHULUAN}

Pendidikan merupakan hal yang mendasar dalam meningkatkan kesejahteraan bangsa, karena pendidikan merupakan tempat penanaman moral, akhlak yang baik, kemandirian, serta pengetahuan 
yang lainnya, dengan pendidikan manusia akan mendapatkan pengalaman yang sangat berharga yang bisa dijadikan acuan ataupun sebagai bekal di kehidupannya.

Pendidikan pada dasarnya diberikan sejak anak usia dini. Menurut National Association for the Education Young Children (NAEYC) menyatakan bahwa anak usia dini merupakan anak yang berapa rentang usia 0-8 tahun. Dalam rentang kehidupan manusia, pada usia tersebut merupakan masa pertumbuhan dan perkembangan yang sangat baik. ${ }^{1}$ Lebih lanjut lagi dijelaskan bahwa PAUD merupakan proses pembinaan tumbuh kembang anak mulai anak lahir hingga usia enam tahun secara menyeluruh dengan memberi rangsangan bagi perkembangan moral dan spiritual, motorik, emosional dan sosial secara tepat agar anak tumbuh dan berkembang secara optimal. ${ }^{2}$

Salah satu tokh Islam yang tersohor namanya di dalam dunia pendidikan salah satunya adalah Al-Ghazali dan Abdullah Nashih Ulwan. Al-Ghazali merupakan salah satu tokoh yang sangat memperhatikan bidang pendidikan bangsa. Beliau merupakan salah satu tokoh pendidikan Islam klasik yang mendapatkan banyak gelar diantaranya yaitu gelar Hujjatul Islam (pembela Islam), Zain al-Din (sang omament agama), Syeikh al-Syufiyyin (Guru besar dalam Tasawuf), dan Imam alMurabbin (Pakar bidang Pendidikan).

Selanjutnya Abdullah Nashih Ulwan merupakan salah satu tokoh pendidikan Islam modern. Kelahiran Abdullah Nashih Ulwan berpaut jauh dengan Al-Ghazali. Beliau merupakan sosok yang sangat cerdas selalu menjadi panutan bagi teman-temannya. Adbullah Nashih Ulwan adalah salah satu tokoh Islam yang memperkenalkan pertama kali mata pelajaran Tarbiyah Islamiyah yang digunakan sebagai dasar dalam belajar di sekolah, sehingga mata pelajaran tersebut menjadi salah satu

\footnotetext{
${ }^{1}$ Ahmad Susanto, Pendidikan Anak Usia Dini Konsep dan Teori (Jakarta: PT Bumi Angkasa, 2017), 1.

${ }^{2}$ Isjoni, Model Pembelajaran Anak Usia Dini (Bandung: Alfabeta, 2010), 20.
} 
mata pelajaran yang wajib diambil oleh murid-murid di sekolah menengah.

\section{METODE PENELITIAN}

Penelitian ini menggunakan pendekatan kualitatif, karena data yang terkumpul dan analisisnya lebih bersifat kualitatif (tidak menggunakan angka-angka). ${ }^{3}$ Penelitian kualitatif merupakan penelitian yang digunakan untuk mendeskripsikan dan menganalisis fenomena, peristiwa, aktivitas sosial, sikap, kepercayaan, persepsi, pemikiran orang secara individual maupun kelompok. Menurut Sukmadinata, dalam penelitian kualitatif data yang diperoleh dihimpun secara seksama, mencakup deskripsi yang mendetail, serta hasil analisis dokumen dan catatan-catatan. ${ }^{4}$

Adapun jenis penelitian yang digunakan dalam penelitian ini adalah library research yaitu telaah yang digunakan untuk memecahkan suatu permasalahan yang pada dasarnya bertumpu pada penelaahan kritis dan mendalam terhadap bahan-bahan pustaka yang relevan. Penelitian seperti ini bahan-bahan pustaka digunakan sebagai sumber ide dalam menggali pemikiran atau pun gagasan baru, sebagai bahan dasar untuk melakukan dedukasi dari pengetahuan yang telh ada, sehingga kerangka teori baru dapat dikembangkan dan dapat digunakan sebagai pemecahan masalah. ${ }^{5}$

Metode pengumpulan data yang digunakan dalam penelitian ini adalah metode dokumen, metode pengumpulan data dokumen merupakan catatan tertulis yang berisi pernyataan yang tertulis yang disusun oleh suatu lembaga atau perseorangan yang untuk keperluan pengujian suatu peristiwa, dan berguna bagi sumber data, bukti, informasi kalamiahan yang sukar diperroleh, sukar ditemukan, dan

3 Sugiyono, Metode Penelitian Pendidikan Pendekatan Kuantitatif, Kualitatif, dan R\&D (Bandung: Alfabeta, 2015), 14.

${ }^{4}$ Bachtiar S. Bachri, "Meyakinkan Validitas Data Melalui Triangulasi Pada Penelitian Kualitatif," Teknologi Pendidikan, 1 (April, 2010), 50.

${ }^{5}$ Tim Penyusun Fakultas Tarbiyah dan Ilmu Keguruan IAIN Ponorogo, Buku Pedoman Penulisan Skripsi (Ponorogo: FATIK IAIN Po, 2018), 53. 
membuka kesempatan untuk lebih memperluas pengetahuan terhadap sesuatu yang diselidiki. ${ }^{6}$

Teknik yang digunakan dalam analisis penelitian ini menggunakan metode content analysis, yaitu analisis data yang mendeskripsikan secara objektif dan sistematis sehingga dapat menarik kesimpulan yang sahih. $^{7}$

\section{PENDIDIKAN ISLAM ANAK USIA DINI PERSPEKTIF AL-GHAZALI}

\section{Riwayat hidup Al-Ghazali}

Nama lengkapnya adalah Abu Hamid Muhammad bin Muhammad Al-Ghazali dilahirkan di Thus di kota Khursan Persia pada tahun $450 \mathrm{H}$ atau $1058 \mathrm{M}$, dan wafat di Tabristan wilayah di provinsi Thus pada 4 Jumadil akhir tahun $505 \mathrm{H} / 1$ Desember 1111 M. ${ }^{8}$ Di masa kanak-kanak Imam Al-Ghazali belajar kepada Ahwad bin Muhammad ar-Radzikani di Thus kemudian belajar kepada Abi Nashr al-Ismaili di Jurjani dan pada akhirnya ia kembali ke Thus lagi. ${ }^{9}$

Al-Ghazali sekolah di madrash yang bernama Madrasah Nizamiyah, yang didirikan oleh Abu Ali Hasan bin Ali Thusi, yang lebih dikenal sebagai Nizam Al Mulk, seorang pedana menteri di masa pemerintahan Dinasti Saljuk. $\mathrm{Di}$ madrasah tersebut Al-Ghazali mempelajari dasar-dasar pengetahuan. Selanjutnya ia pergi ke Nashafur dan Khurasan, dua kota yang dikenal sebagai pusat ilmu pengetahuan terpenting di dunia Islam pada saat itu.di kota tersebutlah Al-Ghazali berguru kepada Imam Al-Haramin Abi Al-Ma'ali Al-Juwainy, seorang ulama yang bermazhab Syafi'i yang menjadi guru besar di Nishfur. ${ }^{10}$

\footnotetext{
${ }^{6}$ Mahmud, Metode Penelitian Pendidikan (Bandung: CV Pustaka Setia, 2011), 183.

${ }^{7}$ Lexy J. Moleong, Metodologi Penelitian Kualitatif (Bandung: PT Remaja Rosdakarya, 2010), 220.

8 Abuddin Nata, Pemikiran Para Tokoh Pendidikan Islam (Jakarta: PT Raja Grafindo Persada, 2000), 81 .

${ }^{9}$ Ahmad Zaini, "Pemikiran Tasawuf Imam Al-Ghazali," Esoterik, 1(2016), 150.

${ }^{10}$ Syamsul Kurniawan \& Erwin Mahrus, Jejak Pemikiran Tokoh Pendidikan Islam (Jogjakarta: Ar-Ruzz Media, 2013), 87-88.
} 
Di antara mata pelajaran yang dipelajarai Al-Ghazali di kota tersebut diantaranya adalah teologi, hukum Islam, filsafat, logika, tasawuf (sufisme), dan ilmu-ilmu alam. Hal ini terlihat dari karya-karyanya yang dibuat dalam berbagai bidang ilmu pengetahuan. Dengan demikian, banyak sekali kehlian yang dikuasai oleh Al-Ghazali, maka tidak heran jika ia mendapat bermacam gelarr yang mengarumkan namanya seperti, gelar Hujjatul Islam (pembela Islam), Zain al-Din (sang omament agama), Syeikh al-Syufiyyin (Guru besar dalam Tasawuf), dan Imam al-Murabbin (Pakar bidang Pendidikan). ${ }^{11}$ Karyanya yang membahas tentant pendidikan Islam anak adalah Ihya' Ulum al Din dan Ayyuhal Walad.

\section{Konsep pendidikan Islam anak usia dini perspektif AI-Ghazali}

Menurut Al-Ghazali dalam pengembangan ilmu pendidikan memiliki beberapa penekanan yang sangat berperan, yang didukung oleh pendidik serta peserta didik. Konsep pendidikan Al-Ghazali pada intinya merupakan pewarisan nilai-nilai budaya masyarakat kepada setiap individu agar kehidupan budaya dapat hidup secara berkesinambungan. Ciri khas yang terdapat di dalam sistem pendidikan Al-Ghazali terletak pada pengajaran moral religius tanpamengabaikan urusan dunia. ${ }^{12}$ Dalam mendidik anak usia dini, Al-Ghazali berpendapat bahwa membimbing anak kecil harus secara bertahap. ${ }^{13}$

Tujuan pendidikan Islam menurut Al-Ghazali adalah agar manusia berilmu. IImu yang bermanfaat yang bisa diterapkan dalam kehidupan sehari-hari serta mencari ridha Allah Swt. ${ }^{14}$

Dalam pendidikan Islam Al-Ghazali menyususn kurikulum pendidikan dirumuskan sesuai dengan ilmu pengetahuan, yang terbagi menjadi beberapa sudut pandang yaitu:

\footnotetext{
11 Alwizar, "Pemikiran Pendidikan Al-Ghazali," Alwizar, 1 (Januari-Juni, 2015), 132.

${ }^{12}$ Miya Rahmawati, "Mendidik Anak Usia Dini Dengan Berlandaskan Pemikiran Tokoh Islam AlGhazali," Al Fitrah, 2 (Januari, 2019), 277.

${ }^{13}$ Imam Abu Hamid Al-Ghazali, Ringkasan Ihya' 'Ulumuddin, terj. Achmad Sunarto (Surabaya: Mutiara Ilmu, 2019), 59.

${ }^{14}$ Syamsul Kurniawan \& Erwin Mahrus, Jejak Pemikiran Tokoh Pendidikan Islam, 92.
} 
a. Berdasarkan pembidangan ilmu, yaitu ilmu Syari'at sebagai ilmu terpuji dan ilmu bukan Syari'at seperti imu kedokteran, ilmu berhitung dan ilmu perusahaan.

b. Berdasarkan objek, dalam hal ini terbagi menjadi ilmu terkutuk seperti ilmu sihir, ilmu nujum, dan ilmu ramalan. Selanjutnya yaitu ilmu terpuji baik sedikit maupun banyak, ilmu yang mengajarkan tata cara mendekatkan diri kepada Allah serta bekal diri di akhirat.

c. Berdasarkan status hukum, dibagi ke dalam fardu 'ain yakni ilmu agama dan cabang-cabangnya, serta fardu kifayah mencakup ilmu kedokteran, pengobatan tradisional, dan jahit menjahit. ${ }^{15}$

Selanjutnya dalam pendidikan Islam anak Al-Ghazali menerapkan beberapa metode diantaranta sebagai berikut:

a. Metode ceramah, metode ini digunakan dalam mendidik anak oleh AlGhazali dengan cara menyampaikan nasehat-nasehat yang berkaitan dengan sifat-sifat terpuji dan tercela kehidupan di dunia dan di akhirat.

b. Metode penuntunan dan hafalan, metode ini dipandang bahwa meode yang digunakan pertama kali untuk mengenalkan kaidah-kaidah di dalam agama, lalu selanjutnya guru menjelaskan tentang arti kaidahkaidah tersebut agar anak memahaminya.

c. Metode diskusi, ketika anak sudah cukup ilmunya dalam berfikir maka metode ini digunakan dalam mendidik anak, sebagaimana yang dilakukan oleh para ulama besar dalam mencari solusi dari sebuah permasalahan dengan berdiskusi. ${ }^{16}$

d. Metode bercerita, metode ini digunakan sebagai cara dalam mendidik anak sebagaimana Al-Ghazali menyuruh muridnya untuk berkumpul dengan orang-orang yang sholeh untuk mendengarkan ceritanya serta meneladani atau meniru akhlaknya. ${ }^{17}$

${ }^{15}$ Rizka Amalia, Filsafat Pendidikan Anak Usia Dini (Yogyakarta: Media Akademi, 2017), 4142.

${ }^{16}$ Imam Al-Ghazali, Ihya 'Ulumuddin, Voll 1 (Semarang: CV Asy Syifa', 1990), 128.

${ }^{17}$ Imam Al-Ghazali, Terjemah Syarah Ayuhal Walad terj. (Surabaya: Mutiara Ilmu 2017), 17. 
e. Metode teladan, hubungan guru dengan murid merupakan ketereratan satu sama lain, dengan demikian murid akan selalu memperhatikan apa yang dilakukan oleh guru, sehingga guru harus bersikap yang baik agar menjadi keteladanan muridnya. ${ }^{18}$

f. Metode pemberian hadiah dan hukuman, dalam menggunakan metode ini digunakan untuk mencapai tujuan dalam pendidikan dann digunakan dengan wajar. Al-Ghazali menjelaskan bahwa untuk tidak berlebihan dalam menghukum anak, karena hal ini akan berdampak pada psikologis anak. ${ }^{19}$

\section{PENDIDIKAN ISLAM ANAK USIA DINI PERSPEKTIF ABDULLAH NASHIH ULWAN}

\section{Riwayat hidup Abdullah Nashih Ulwan}

Abdullah Nashih Ulwan lahir di kota Halab Suriah pada tahun 1928, tepatnya di daerah Qodhi Askar yang terleak di Bandar Halab Syiria. Nama lengkapnya adalah Al-Ustadz Syaikh Abdullah Nashih Ulwan, selanjutnya disebut dengan Nashih Ulwan. ${ }^{20}$

Sejak usia 15 tahun Abdullah Nashih Ulwan sudah menguasai ilmu Bahasa Arab dan mulai menghfal Al-Qur'an. Kecerdasannya membuatnya menjadi umpuan rujukan bagi teman-temannya. Beliau aktif sebagai da'i di sekolah-sekolah dan masjid-masjid di daerah Halab. Setelah menyelesaikan jenjang pendidikan di Sekolah Dasar dan Sekolah Lanjut Tingkat Pertama, beliau melanjutkan ke Sekolah Tingkat Atas di Halab pada tahun 1949 jurusan IImu Syari'ah dan Pengetahuan Alam. ${ }^{21}$

Kemudian Nashih Ulwan melanjutkan studinya di Al-Azhar University Mesir dengan mengambil jurusan Ushuludin selesai pada tahun

\footnotetext{
${ }^{18}$ Nata, Pemikiran Para Tokoh Pendidikan Islam, 94.

${ }^{19}$ Imam Al-Ghazali, Ihya 'Ulumuddin, Voll 1, 178.

20 Ahmad Atabik\&Ahmad Burhanuddin, "Konsep Nasih Ulwah tentang pendidikan anak," Elementary, 2 (Juli-Desember, 2005), 276.

${ }^{21}$ Amalia, Filsafat Pendidikan Anak Usia Dini, 58.
} 
1952. Selanjutnya melanjutkan studi S2 di perguruan tinggi pada tahun 1954 di bidang pendidikan setara dengan Master of Art (MA). ${ }^{22}$ Pada tahun 1982 beliau berhasil mendapatkan gelar Doktor di Universitas AlSand Pakistan.

Setelah menerima gelar Doktor di Pakistan Abdullah Nashih Ulwan pulang, beliau merasakan sakit dibagian dadanya, beliau dirawat di rumah sakit karena ada permasalahan pada bagian hati dan paru-parunya. Abdullah Nashih Ulwan meninggal pada tanggal 5 muharam $1408 \mathrm{H}$ tepatnya 29 Agustus 1987 M di rumah sakit Universitas Malk Abdul Aziz Jeddah Arab Saudi pada usia 59 tahun, jenazahnya di kebumikan di Makkah. ${ }^{23}$

Secara garis besar karya-karya Abdullah Nashih Ulwan adalah sebagai berikut:

a. Bidang pendidikan dan pengajaran, meliputi: Tarbiyah al-aulad fi alIslam, Hukum al-Islam fi al-Tilfiziyyun, Ila Waratsati al-Anbiya'i, Hatta Ya'lama al-Syabab.

b. Bidang figh dan muamalah, meliputi: Fadhail al-Shiyam wa Ahkamuh, Ahkam al-Zakat, Adab al-khitbah wa al-zafaf wa Huquq al-Zaujain 'Aqabat al Zawaj wa thuruqu Mu'ajalatiha 'ala Dawai al-Islam, Hukm alIslam fi Wasail al-Ham, Al-Islam Syariat al-Zaman wa al-Makan.

c. Bidang akidah, meliputi: Syubuhat wa Rudud Haula al-Aqidah ea Ashl al-Irtsan dan Huriyah al-l'tiqad fi al-Syari'ah.

d. Bidang umum, meliputi: Al-Takaful al-Ijtima'i fi al-Islam, Shalahuddin alAyyubi, Ahkam al-Ta'min, Takwin al-Syahsyiyyah al-Insaniyyah fi Nazhair al-Islam, Al-Qoumiyyah fi Mizan al-Islam.

${ }^{22} \mathrm{Ibid}, 58$.

${ }^{23} \mathrm{Ibid}, 59$. 


\section{Konsep pendidikan islam anak usia dini Abdullah Nashih Ulwan}

Pendidikan yang di ajarkan oleh Abdullah Nashih Ulwan disesuaikan dengan pendidikan yang diajarkan oleh Nabi Muhammad SAW. Anak merupakan tanggung jawab dari orang tua. Sebagai seorang muslim orang tua harus bersikap amanah dalam mendidik anak. dalam mendidik anak, orang tua juga dapat menyerahkannya kepada orang lain yang dirasa mampu mendidik anak dengan baik. ${ }^{24}$

Dalam pendidikan Abdullah Nashih Ulwan terdapat materi-materi yang di gunakan dalam mendidik anak, diantaranya adalah sebagai berikut:

a. Pendidikan iman, pendidikan iman menjadi salah satu pendidikan yang harus diajarkan kepada anak, hal ini berkaitan dengan rukun iman serta rukun Islam, aqidah dan ibadah. Hal tersebut menjadi satu kesatuan dalam pengenalan dasar keimanan bagi anak. ${ }^{25}$

b. Pendidikan moral, merupakan salah satu prinsip yang harus dimiliki serta dijadikan sebagai kebiasaan mulai anak masih pemula hingga anak sudah dewasa. Ketika anak sudah terbiasa tumbuh berrdasarkan keimanan maka anak akan selalu taat kepada Allah serta memiliki bekal dan kemampuan di dalam menerima setiap kemuliaan disamping berakhlak mulia. ${ }^{26}$

c. Pendidikan fisik, hal ini adalah satu hal yang harus dipenuhi oleh orang tua demi kelangsungan pertumbuhan fisik anak yang kuat, sehat, bergairah, dan bersemangat. Kewajiban-kewajiban tersebut berupa memberikan nafkah kepada anak, memperhatikan pola makan dan tidur, melindungi anak dari penyakit menular, membiasakan anak untuk berolah raga dan lain sebagainya. ${ }^{27}$

\footnotetext{
24 Ahmad Atabik\&Ahmad Burhanuddin, "Konsep Nasih Ulwah tentang pendidikan anak," Elementary, 2 (Juli-Desember, 2005), 281.

${ }_{25}$ Abdullah Nashih Ulwan, Pendidikan Anak dalam Islam, terj. Jamaluddin Miri Lc (Jakarta: Pustaka Amani, 2007) Voll 1, 165.

${ }^{26}$ Ibid, 198.

${ }^{27}$ Ibid, 245.
} 
d. Pendidikan rasio (akal), dalam hal ini Abdullah Nashih Ulwan berpendaapat bahwa pendidikan rasio (akal) terfokus menjadi tiga permasalahan yaitu: (1) kewajiban mengajar, yakni memberi pembekalan ilmu pengetahuan dan budaya, serta memusatkan pemikiraannya secara mendalam; (2) menumbuhkan kesadaran berfikir anak; dan (3) memelihara kesehatan rasio anak, orang tua memperhatikan kesehatan akal anak agar pemikiran anak ttetap jernih dan matang. 28

e. Pendidikan kejiwaan, tujuan dari pendidikan ini adalah membentuk, membina, serta menyeimbangkan kepribadian anak sehingga ketika anak sudah dewasa ia mampu bertanggung jawab dengan tugas yang diberikan kepadanya. ${ }^{29}$

f. Pendidikan sosial, menurut Abdullah Nashih Ulwan pendidikan ini harus diberikan anak sejak usia dini, karena dengan demikian ketika anak sudah dewasa hidup di tengah-tengah masyarakay dapat berinteraksi sosial dengan baik, serta memiliki tindakan yang bijaksana dan matang. 30

g. Pendidikan seksual, pokok-pokok pendidikan seksual yang diberikan kepada anak yaitu: menanamkan rasa malu; menanamkan jiwa maskulitas dan feminitas; memisahkan tempat tidur laki-laki dan perempuan; mengenalkan waktu berkunjung; dan pendidikan kebersihan alat kelamin. ${ }^{31}$

Selanjutnya metode yang digunakan Abdullah Nashih Ulwan dalam mendidik anak adalah sebagai berikut:

a. Pendidikan dengan keteladanan, menurut Abdullah Nashiih Ulwan metode ini sangat efektif digunakan dalam mendidik anak untuk mempersiapkan serta membentuk moral anak, spriritual, sosial. Dalam

\footnotetext{
${ }^{28}$ Ibid, 301.

${ }^{29}$ Ibid, 363.

${ }^{30}$ Ibid, 436.

${ }^{31}$ Amalia, Filsafat Pendidikan Anak Usia Dini, 69-70.
} 
hal ini pendidik menjadi contoh ideal bagi anak. Dengan keteladanan anak akan melakukan imitasi dengan apa yang dilakukan, diikuti serta apa yang dilakukannya. ${ }^{32}$

b. Pendidikan dengan kebiasaan (pengulangan), pembiasaan memiliki peluang yang besar dalam mendidik anak, karena dengan membiasakan anak sedak dini akan menjadi sebuah kebiasaan dalam melakukan suatu hal ketika sudah dewasa. Dengan demikian, pendidik harus memperhatikan pengajaran pada anak dalam kebaikan dan penerapannya. ${ }^{33}$

c. Pendidikan dengan nasehat, dengan menggunakan metode ini dapat membuka hati anak, mendorong anak menuju ke hal-hal yang positif, mengisi dengan akhlak yang mulia, dan menyadarkan anak pada prinsip-prinsip islam. ${ }^{34}$

d. Metode pemberian perlatihan dan pengawasan, pendidikan dengan pemberian perhatian merupakan pendidikan yang berpusat penuh dengan memperhatikan setiap perkembangan akidah dan moral anak, serta situasi pendidikam jasmani dan kemampuan ilmiah anak. Dengan demikian anak akan memiliki pondasi Islam yang kooh. ${ }^{35}$

e. Pendidikan dengan hukuman, dalam hal ini ada beberapa hal yang harus diperhatikan dalam memberikan menurut Islam yaitu: 1) Lemah lembut dan kasih sayang sebagai dasar pembenahan anak; 2) Menjaga tabiat anak saat menggunakan hukuman; 3) Harus dilakukan secara bertahap mulai dari yang paling ringan hingga yang paling keras. ${ }^{36}$

\footnotetext{
${ }^{32}$ Mulyadhi Kartanegara, Pemikiran Islam Kontemporer (Yogyakarta: Jendela, 2003), 43.

${ }^{33}$ Abdullah Nashih Ulwan, Pendidikan Anak dalam Islam, terj. Jamaluddin Miri Lc (Jakarta: Pustaka Amani, 2007) Voll 2, 203.

${ }^{34}$ Agus setiawan, "Metode Pendidikan Islam Masa Kini Dalam Keluarga Perspektif Abdullah Nashih Ulwan," EDUCASIA, 2 (2016), 146.

${ }^{35}$ Ulwan, Pendidikan Anak dalam Islam, voll 2, 275.

${ }^{36} \mathrm{Ibid}, 312$.
} 
WISDOM: JURNAL PENDIDIKAN ANAK USIA DINI

Volume 01 No. 01, Juni 2020

Jika konsep tentang pendidikan Islam anak usia dini dibandingkan antara keduanya, maka dapat dijelaskan secara ringkas dalam tabel berikt ini:

Tabel 1. Konsep pendidikan Islam anak usia dini perspektif Al-Ghazali dan Abdullah Nashih Ulwan

\begin{tabular}{|c|c|c|}
\hline Aspek & Al-Ghazali & Abdullah Nashih Ulwan \\
\hline $\begin{array}{l}\text { Tujuan } \\
\text { pendidikan }\end{array}$ & $\begin{array}{l}\text { Tujuan dari pendidikan islam } \\
\text { anak usia dini Al-Ghazali } \\
\text { adalah agar manusia berilmu, } \\
\text { selain itu dapat diterrapkan } \\
\text { dalam kehidupan sehari-hari. } \\
\text { Selain itu akhir dari tujuan } \\
\text { pendidikan adalah } \\
\text { kesempurnaan insani yang } \\
\text { mendekatkan diri kepada sang } \\
\text { pencipta Allah Swt. }\end{array}$ & $\begin{array}{l}\text { Tujuan pendidikan Isllam anak } \\
\text { usia dini Abdullah Nashih } \\
\text { Ulwan adalah agar anak } \\
\text { memiliki sifat spiritual yang baik } \\
\text { dan memiliki ketaatan kepada } \\
\text { Allah Swt. }\end{array}$ \\
\hline Kurikulum/Materi & $\begin{array}{l}\text { Dalam kurikulum pendidikan Al- } \\
\text { Ghazali membagii ilmu } \\
\text { pengetahuan menjadi beberapa } \\
\text { sudut pandang: } \\
\text { Berdasarkan pembidangan } \\
\text { IImu, yang terbagi menjadi } 2 \\
\text { bagian yaitu IImu Syari'at } \\
\text { sebagai ilmu yang terpuji dan } \\
\text { bukan IImu Syari'at; (2) } \\
\text { Berdasarkan objeknya; dan (3) } \\
\text { Berdasarkan status hukum. }\end{array}$ & $\begin{array}{l}\text { Materi pendidikan yang } \\
\text { disampaikan oleh Abdullah } \\
\text { Nashih Ulwan diantaranya } \\
\text { adalah pendidikan iman, } \\
\text { pendidikan moral, pendidikan } \\
\text { fisik, pendidikn rasio (akal), } \\
\text { pendidikan kejiwaan dan } \\
\text { pendidikn seksual. }\end{array}$ \\
\hline Metode mendidik & $\begin{array}{l}\text { Metode yang digunakan Al- } \\
\text { Ghazali dalam mendidik Islam } \\
\text { anak usia dini yaitu, metode } \\
\text { ceramah, metode penuntunan } \\
\text { dan hafalan, metode diskusi, } \\
\text { metode bercerita, metode } \\
\text { teladan, metode pemberian } \\
\text { hadiah dan hukuman. }\end{array}$ & $\begin{array}{l}\text { Dalam pendidikan Islam anak } \\
\text { usia dini Abdullah Nashih } \\
\text { Ulwan metode yang digunakan } \\
\text { yaitu: pendidikan dengan } \\
\text { keteladanan, pendidikan } \\
\text { dengan } \\
\text { (pengulangan), pendidikan } \\
\text { dengan nasehat, metode } \\
\text { pemberian pelatihan dan } \\
\text { pengawasan, pendidikan } \\
\text { dengan hukuman. }\end{array}$ \\
\hline
\end{tabular}




\section{KESIMPULAN}

Al-Ghazali dan Abdullah Nashih Ulwan merupakan tokoh pendidikan Islam anak yang memiliki pandangan bahwa tujuan pendidikan yang paling utama adalah pendidikan spiritual yang dapat mendekatkan diri kepada sang pencipta yakni Allah Swt. Dalam pendidikan anak usia orang tua adalah orang yang memiliki peran utama dalam mendidik, ketika anak harus dididik oleh orang lain maka harus diserahkan kepada orang yang dianggap mampu untuk mendidik anak dengan baik. Dalam kurikulum/materi yang digunakan Al-Ghazali dan Abdullah Nashih Ulwan memiliki perbedaan, dalam kurikulum yang digunakan AI-Ghazali dibagi bedasarkan IImu pengetahuan, sedangkan materi pendidikan yang digunakan oleh Abdullah Nashih Ulwan lebih luas berdasarkan kondisi pendidikan pada masanya. Selanjutnya metode yang digunakan dalam mendidik anak usia dini metode yang sama-sama digunakan oleh keduanya yaitu metode nsehat/cerita, metode keteladanan, metode pembiasaan, metode pemberian tugas, metode hadiah dan hukuman.

\section{DAFTAR PUSTAKA}

Al-Ghazali Imam Abu Hamid. 2019. Ringkasan Ihya' 'Ulumuddin, terj. Achmad Sunarto. Surabaya: Mutiara IImu

Al-Ghazali Imam. 1990. Ihya 'Ulumuddin, Voll 1. Semarang: CV Asy Syifa'

Al-Ghazali Imam. 2017. Terjemah Syarah Ayuhal Walad terj. Surabaya: Mutiara IImu

Alwizar. "Pemikiran Pendidikan Al-Ghazali," Alwizar, 1 Januari-Juni, 2015

Amalia Rizka. 2017. Filsafat Pendidikan Anak Usia Dini. Yogyakarta: Media Akademi

Bachri Bachtiar S. "Meyakinkan Validitas Data Melalui Triangulasi Pada Penelitian Kualitatif," Teknologi Pendidikan, 1 April 2010

Burhanuddin Ahmad Atabik\&Ahmad, "Konsep Nasih Ulwah tentang pendidikan anak," Elementary, 2 Juli-Desember, 2005 
WISDOM: JURNAL PENDIDIKAN ANAK USIA DINI

Volume 01 No. 01, Juni 2020

Isjoni. 2010. Model Pembelajaran Anak Usia Dini. Bandung: Alfabeta

Mahmud. 2011. Metode Penelitian Pendidikan. Bandung: CV Pustaka Setia

Mahrus Syamsul Kurniawan \& Erwin. 2013. Jejak Pemikiran Tokoh Pendidikan Islam. Jogjakarta: Ar-Ruzz Media

Moleong Lexy J. 2010. Metodologi Penelitian Kualitatif . Bandung: PT Remaja Rosdakarya

Mulyadhi Kartanegara. 2003. Pemikiran Islam Kontemporer. Yogyakarta: Jendela

Nata Abuddin. 2000. Pemikiran Para Tokoh Pendidikan Islam. Jakarta: PT Raja Grafindo Persada

Rahmawati Miya. "Mendidik Anak Usia Dini Dengan Berlandaskan Pemikiran Tokoh Islam Al-Ghazali," Al Fitrah, 2 Januari, 2019

setiawan Agus, "Metode Pendidikan Islam Masa Kini Dalam Keluarga Perspektif Abdullah Nashih Ulwan," EDUCASIA, 22016

Sugiyono. 2015. Metode Penelitian Pendidikan Pendekatan Kuantitatif, Kualitatif, dan $R \& D$. Bandung: Alfabeta

Susanto Ahmad. 2017. Pendidikan Anak Usia Dini Konsep dan Teori. Jakarta: PT Bumi Angkasa

Tim Penyusun Fakultas Tarbiyah dan IImu Keguruan IAIN Ponorogo, Buku Pedoman Penulisan Skripsi Ponorogo: FATIK IAIN Po 2018

Ulwan Abdullah Nashih. 2007. Pendidikan Anak dalam Islam, terj. Jamaluddin Miri Lc. Jakarta: Pustaka Amani Voll 1

Ulwan Abdullah Nashih. 2007. Pendidikan Anak dalam Islam, terj. Jamaluddin Miri Lc. Jakarta: Pustaka Amani Voll

Zaini Ahmad, "Pemikiran Tasawuf Imam Al-Ghazali," Esoterik, 12016 